DOI: https://doi.org/10.34069/AI/2021.47.11.8

How to Cite:

Holubnycha, L., Khodakovska, O., Besarab, T., Dolgusheva, O., \& Malieieva, T. (2021). Psychological impact of online learning during covid-19 pandemic on students' mental health as life quality basis. Amazonia Investiga, 10(47), 70-80. https://doi.org/10.34069/AI/2021.47.11.8

\title{
Psychological impact of online learning during covid-19 pandemic on students' mental health as life quality basis
}

\section{Психологічний вплив онлайн-навчання під час пандемії COVID-19 на психічне здоров'я студентів як основу якості їхнього життя}

Received: October 102021

Abstract

The article describes current problems of students' life quality connected with online learning caused by Covid-19 pandemic and related quarantine. Since online learning can be considered stressful, and that pandemics and quarantine restrictions increase its impact on students' emotional and mental health as a basis for their quality of life, it is significant to discover their impact. The purpose of the research is to examine changing in students' mental health during two periods of online learning. 258 students of Yaroslav Mudryi National Law University (Ukraine) became the sample group. Quantitative and qualitative methods have been used to achieve the purpose. The results have revealed that a rate of stress and an anxiety level among students have grown drastically comparing the first and the second online learning periods. The major conclusion is that experiencing stress, caused by online learning in terms of the pandemic and quarantine, a persons' psychological well-being is badly influenced and can lead to depression. Practical
Accepted: November 30, 2021

Written by:

Liudmyla Holubnycha ${ }^{34}$ https://orcid.org/0000-0002-8252-9893

Oksana Khodakovska ${ }^{35}$ https://orcid.org/0000-0002-2168-4558

Tetiana Besarab ${ }^{36}$ https://orcid.org/0000-0002-3667-3886

Olga Dolgusheva ${ }^{37}$ https://orcid.org/0000-0001-9558-5846

Tetiana Malieieva ${ }^{38}$ https://orcid.org/0000-0001-8614-474X

\footnotetext{
${ }^{34}$ Doctor of Pedagogical Sciences, Professor, Professor of the Department of Foreign Languages \# 3, Yaroslav Mudryi National Law University, Ukraine.

${ }^{35} \mathrm{PhD}$, Associate Professor, Department of Foreign Languages \# 1, Yaroslav Mudryi National Law University, Ukraine.

${ }^{36} \mathrm{PhD}$, Associate Professor, Department of Foreign Languages \# 3, Yaroslav Mudryi National Law University, Ukraine.

${ }^{37} \mathrm{PhD}$, Associate Professor, Department of Germanic Languages and Teaching Methodology, Volodymyr Vynnychenko Central Ukrainian State Pedagogical University, Ukraine.

${ }^{38}$ Senior Teacher of the Department of Foreign Languages \# 2, Yaroslav Mudryi National Law University, Ukraine.
} 


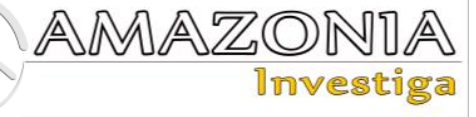

recommendations to reduce stress and psychological problems have been proposed.

Keywords: Emotional and Mental Health, Students, Online Learning, Quality of Life, Pandemic.

\section{Introduction}

Modern world has faced an unprecedented challenge: an outbreak of Covid-19, which has affected global sustainable development significantly, as it has influenced the life, wellbeing and development of every person, moreover, this pandemic led to stress. Symptoms of it as well as increasing anxiety, fatigue, helplessness, boredom, loneliness and depression due to isolation and lack of social contacts, changes in people's habitual activities and lifestyle, impossibility to enjoy certain preferred activities are mentioned as those having influenced on emergence of emotional numbness or demoralization together with behavioural disorders (Brooks, Webster, \& Smith, 2020; Lai, Ma, \& Wang, 2020; London, 2020) and there is no doubt that all the above have worsened quality of life especially regarding its emotional side. Moreover, more and more people around the world are experiencing mental health problems, and today they are affecting everyone.

The investigation of changes in mental and emotional health of students as the basis of their life quality is especially expedient because, on the one hand, emotional stability of young people is vital for sustainable development of the world, on the other hand, they have faced additional impact on their mental health and emotional sphere caused by a change in the form of education: from traditional one into different forms of distance learning. Since it absorbs the best features of traditional forms (full-time, parttime, and external) and may be integrated well with them and as distance learning is a high-tech product of the scientific and technological revolution that uses the idea of continuous service to students, in the terms of the pandemic the vast majority of educational institutions have chosen it and started working online using various UNESCO platforms (2020). So, online form of distance learning has become a special pedagogical technology of the pandemic, based on open learning with the use of modern telecommunications for "student - teacher", "student - student", "student - information" communication in the information space. добробут людей і може призвести до депресії. Запропоновано практичні рекомендації щодо зменшення стресу та психологічних проблем.

Ключові слова: Емоційне та психічне здоров'я, Студенти, Онлайн навчання, Якість життя, Пандемія.

Despite asynchronous and synchronous types of distance learning have been organized more or less properly, online learning has become excessive and prevalent, and consequently, mental and emotional health of students as well as their life quality around the world have been affected. Such psychological issues often prevent students from adapting to online learning. Moreover, a tremendous effect of pandemic (and everything connected with it) on psychophysical state, emotional life and health of young adults creates significant tension for an organism, which alongside with other negative factors leads first to diseases, functional disorders and later to development of organ pathology. The sharp rise in the number of depression, anxiety, fatigue etc. among the young population may happen. Deterioration of the quality of the emotional state can be considered as the manifestation of the psychological effects of Covid-19 epidemic which may be seen in the long term. So the importance of providing psychosocial support to people in order to strengthen their mental health during the Covid-19 outbreak was proposed by various organizations worldwide. Thus, mental and emotional health of young adults as one of the main components of their life quality is crucial for society and future global development, so the impact of pandemic on psychophysical health, which happens during several periods of online learning, is very topical to be investigated by medical, psychological and educational sciences.

Thus the purpose of the manuscript is to examine changing in mental and emotional health of students as the basis of their life quality during two periods of online learning caused by Covid19 pandemic.

The tasks are:

1) to find out the essence of the concepts of "mental health" and "quality of life" and to examine what unconventional (inexperienced before) factors affect the mental health of students nowadays;

2) to analyse mental and emotional changes (in particular as for rate of stress and anxiety 
level) caused by two periods of distance online learning in terms of the pandemic.

\section{Literature Review}

The analysis of researches in medicine, psychology and educational sciences showed a great concern of researchers in the problem discussed. Interconnection between quality of life and emotional intelligence attracted attention of A. Al-Huwailah (2017), C. Pocnet, M. Dupuis, A. Congard, \& D. Jopp (2017), M. Saei Ghare Naz, F. Ramezani Tehrani, T. Behroozi Lak, F. Mohammadzadeh, M. Nasiri, F. Kholosi Badr, \& G. Ozgoli (2020) and others. Important issues of saving and preserving students' health as the aim of teaching staff activity were thoroughly studied by A. Aristovnik, D. Keržič, D. Ravšelj, N. Tomaževič, \& L. Umek. (2020), L. Holubnycha, S. Miasoiedova, \& K. Nesterenko (2018), M. Mukhin, M. Sergeeva, \& N. Ogurechnikova. (2020), S. Khatuntseva, N. Kabus, M. Portyan, O. Zhernovnykova, S. Kara, \& S. Knysh (2020) and others. The ways external dangers and disasters affected an educational system and the degree the pandemic restrictions changed and challenged the educational process on the whole were revealed in the studies conducted by $\mathrm{M}$. Akat and K. Karataş (2020), A. Bozkurt and R. Sharma (2020) and others. Impact on the students' mental and emotional well-being caused by certain conditions connected with the Covid-19 pandemic and its correlation with distance online learning were investigated by $\mathrm{A}$. Al-Rabiaah, M. Temsah, A. Al-Eyadhy, G. Hasan, F. Al-Zamil, S. Al-Subaie et al. (2020), M. Savage, R. James, D. Magistro, J. Donaldson, L. Healy, M Nevill et al. (2020). Interrelation of the Covid-19 pandemic and mental health problems concerning young adults were reflected by J. Lai et al. (2020), M. Nicola, Z. Alsafi, C. Sohrabi, A. Kerwan, A. Al-Jabir, C. Iosifidis et al. (2020), S. Sood (2020), C. Son, S. Hegde, A. Smith, X. Wang, \& F. Sasangohar (2020), W. Cao, Z. Fang, G. Hou, M. Han, X. Xu, \& J. Dong (2020), C. Wang, R. Pan, X. Wan, Y. Tan, L. Xu, C. Ho et al. (2020) and others.

However, the gradual impact of online learning during pandemic on mental and emotional health of young adults as the basis of their life quality (throughout two periods of distance learning) has not been thoroughly investigated.

The hypothesis of our research is based on the assumption that due to the quarantine aimed at reducing the disaster of the Covid-19 pandemic and followed by introduction of distance online learning measures young people could have been exposed to negative psychological problems which may worsen over time.

\section{Methodology}

According to the purpose of the research both quantitative and qualitative methods have been used to investigate and measure the dominant traits in the dynamics of mental health and emotional state changes affected by the online learning process in higher educational institutions during the lockdown and quarantine period. Fiesher's statistical test has been applied to assess the reliability of the results of the representative sample; and Bonferroni correction has been taken to control the group error probability. To analyse and compare the findings, the authors have used the Patient Health Questionnaire-9

(PHQ-9)

(https://patient.info/doctor/patient-health-

questionnarire-phq-9) and Generalized Anxiety Disorder $\quad$ Scale-7 $\quad$ (GAD-7) (https://www.mdcalc.com/gad-7-general-

anxiety-disorder-7). The obtained data include comparative and descriptive statistics on all issues and are represented using Microsoft Excel.

Calculations were made using statistical calculator (https://www.calculator.net/statisticscalculator.html). The results of the research were obtained with the informed consent of all the participants.

\section{Participants}

This study was conducted in several Institutes (the Institute of the Prosecutor's Office and Criminal Justice, the Institute of Training Personnel for Justice Authorities) and faculties (Faculty of Economics and Law, Faculty of the Bar) of Yaroslav Mudryi National Law University, Kharkiv, Ukraine. The target group of students included 258 respondents of the first and second year of study. They were asked to take part in completing the questionnaires online responding independently and anonymously.

The research was conducted from March 2020 to January 2021 and consisted of two stages, according to the quantity of online learning periods. The first stage of the study was held during the First Period (FP) (March - June 2020) and the first questionnaire was conducted at the end of June 2020 to measure mental and emotional changes caused by FP of online learning in the terms of the pandemic and quarantine. The second part of the research was performed during the Second Period (SP) (October 2020 - January 2021) and was ended by 


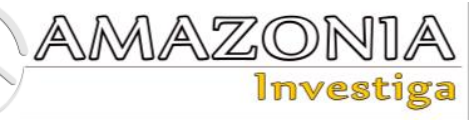

the second questionnaire at the end of January 2021 to measure mental and emotional state of the students after SP and to analyse changing in their mental and emotional health during two periods of online learning caused by Covid-19 pandemic.

The total number of respondents in the FP and in the SP groups was equal, an average age of the students was 18 (ranging from 17 to 19). As the respondents were the same, age distribution in FP and SP could not be equal: it was 17 in the FP and it became 18.5 in the SP respectively. The gender distribution equalled to $65.0 \%$ male and $35.0 \%$ female participants

\section{Theoretical background}

Concept of quality of life differs significantly for people of different social and cultural strata and depends on their idea of what is good and the variety of life aspects in which a person manifests himself. However, there is no doubt that emotional and mental state of a person affects his life satisfaction. Human life without emotions (i.e. mental states) is impossible. Emotions reveal a positive or negative attitude of a person to the world around him or evaluation of quality of his life. Without emotions, purposeful human activity may be guessed as impossible. Positive emotions determine a positive assessment of the object or the phenomenon that motivates a person to work and achieve a useful result.

According to P. Theofilou, the evaluation of life quality includes emotional reaction of a person to everything that happens in his life, as well as his mood, feelings of life and satisfaction with it, job satisfaction and personal relationships. The researcher also makes a suggestion that person's general health influences quality of his life (2013).

Considering quality of life the World Health Organization (WHO) studies and defines it in close connection with mental health. WHO proposes to understand the notion under research as people's perception of their position in life depending on cultural characteristics and values and in connection with their goals, expectations, standards, concerns (WHOQOL Group, 1997).

Speaking about mental health, definition presented by WHO is the following: mental health is such a state of well-being in which people realize their abilities, can withstand the stress of life, work effectively, and contribute to their community (WHO, 2004). Mental health can be understood as the "core" of human health: a state of complete physical, mental and social well-being, not merely the absence of disease or infirmity. In this positive sense, mental health, which is determined by biological, psychological and social factors, is the basis of an individual's well-being and effective community functioning. So it is natural that mental health protection and preservation is considered to be one of the main elements of different spheres of human life including modern pedagogy and psychology that are aimed at creating an environment of support, which improves quality of life of students as well as strengthens resistance to stress, teaches to take care of yourself and others.

In the course of pandemic and quarantine restrictions specialists are very anxious about various challenges that have an impact on a young person's health and mental well-being as, on the one hand, young people are the future of our world; on the other hand, social relations are especially crucial in this period of human life and determine quality of students' life as drastically limit the number of events in their life, reduce feelings of life fulfillment, restrict personal relations and consequently satisfaction with it. But all preventive measures that were brought into effect in order to cope with the virus resulted in self-isolation, travel restrictions and lockdowns. The abovementioned could not but affect the psychological state of young people.

Moreover, the Covid-19 outbreak deeply affected global education and forced educational establishments to change the forms of education rather strictly and to start working online using various technologies to cover the learning needs. Outcomes of this process can be described as rather questionable.

Psychological impact of online learning (which is used instead of traditional forms of education in the world now) on students' mental and emotional health is, firstly, due to the problems of emotional rupture of living contact coursed by transformation of interaction between people, which is mediated by the use of technical information tools in the main sphere of young people's activity - getting an education. Besides, as in distance learning the main element of educational activity is independent work of a student, it enhances the feeling of loneliness and lack of communication with group mates. While live communication is vital for a person as a social being especially in the period of social formation that mostly occurs during student age. In addition, the constant focus on technical means, on the virtual environment, continuous 
concentration on the monitor screen, long-term inclusion in the virtual world that have become usual in distance forms of learning cannot but be reflected in the internal state of the student as well as his quality of life.

What is more, existence of a student and his successful functioning in the new psychological environment puts forward a number of specific requirements that increase mental stress. They are the following: 1) the ability to extract and filter information from a large flow of information; 2) the ability to briefly, accurately and competently formulate messages or requests; 3) the ability to properly distribute load and quickly process the received information. The fragmentation of information leads to an increase in cognitive load on a student. While personal, live communication becomes short-term, superficial, its emotional component is impoverished; the accumulation of information begins to take longer than its discussion; the time when a person in communication can express himself as an individual is reduced; the time of role, official communication increases (Pidchasov, 2016).

So, it is becoming increasingly clear that the process of interaction of the young individual during online learning affects his psyche. Moreover, dramatic changes that have taken place in recent times in all spheres of life of modern society have made the situation worse in the psychological context.

Paying attention that the basis of educational and cognitive activities is psychological processes of a personality based not only on pedagogical but also socio-psychological issues which must be stated and solved adequately, the connection between the student and the teacher in online learning should provide the student with psychological comfort. The essence of the feedback mechanism is that in interpersonal communication the process of information exchange seems to be doubled and, in addition to the content load, carries from the recipient to the communicator information about how the recipient perceives and evaluates the behaviour of the communicator. The adequacy of the perception of information depends on many reasons, the most important of which is the presence or absence of communication barriers in the dialogue process. The communication barrier is a psychological barrier to the adequate transmission of information between the participants. Taking into account psychological features in construction of the process of online learning is an urgent and important psychological and pedagogical task.

Therefore, on the one hand, distance learning accessibility, affordability and / or flexibility enabled quick transition to new learning environment. But on the other hand, the above mentioned its psychological features and requirements together with social distancing, restrictions to stay at home, modern technology errors and not satisfactory internet connection, lack of personal interaction as well as inability (both financial and technical) to use all devices necessary for mastering the educational program are considered to be one of the crucial problems the students face nowadays. Sedentary behaviour that most of the participants of the educational process had to follow, led to obvious health risks (Michielsen et al, 2003). The above stressful factors led to increasing fatigue, boredom, anxiety and depression, which affect the level of mental health that is determined not only by biological but also psychological as well as social factors (Galderisi, Heinz, Kastrup, Beezhold, \& Sartorius, 2015).

Thus, considering the question what affects the quality of life of students through their mental health most of all nowadays, three unusual (inexperienced before) aspects should be mentioned from our point of view. They are the following: 1) pandemic, which gave birth to fear for life and health of loved ones and their own; 2) quarantine measures that severely restricted social contacts and changed the usual course of life; 3) distance learning, which transformed necessary educational interaction and coursed additional challenges.

\section{Description of the technology}

To analyse mental and emotional changes caused by two periods of distance online learning in terms of the pandemic two criteria were examined namely rate of stress, which leads to depression, and anxiety level. To assess the severity of depression among the respondents the Patient Health Questionnaire-9 (PHQ-9) was applied by the authors. Each PHQ module was used in conjunction with other modules, as part of a complete PHQ. PHQ-9 contains questions about additional (neurovegetative, cognitive, psychomotor) symptoms of depression. Each of the statements presented in the questionnaires can be assessed by the subjects in the range from 0 ("not once") to 3 points ("almost every day). The depression severity is scored as follows: 0-4 none, 5-9 mild, 10-14 moderate, 15-19 moderately severe, 20-27 severe. Respondents 


\section{$\frac{\text { AMAZONDA }}{\text { Drvestiga }}$}

having higher than 10 scores rating are classified as depressed (Kroenke, Spitzer, Williams, \& Löwe, 2010). PHQ-9 manifests rather satisfactory internal consistency (Cronbach's a = 0.890).

Generalized Anxiety Disorder Scale-7 (GAD-7) is a screening psychological rapid technique for early diagnosis of generalized anxiety. It includes 7 items aimed at identifying and measuring panic, social anxiety. It was modelled and developed by R. Spitzer, K. Kroenke, J. Williams, \& B. Löwe (2006). The method has good reliability, factorial and concurrent validity and is used in the diagnosis of generalized anxiety disorder and other conditions accompanied by anxiety. The GAD-7 points of 5 , 10 , and 15 might be interpreted as representing mild, moderate, and severe levels of anxiety and can be compared to levels of depression on the PHQ-9. A respondent has to choose one of the categories of "not at all," "several days," "more than half the days," and "nearly every day," while answering the questions. The points range from 0 to 21. The Scale manifested very good internal consistency (Cronbach's $a=0.905$ ).

\section{Results and Discussion}

During the analysis of the results, the sensitivity and the specific PHQ-9 and GAD-7 questionnaires, predictive value the probability of a positive result, as well as the probability false negative result were taken into account. Predictive value was interpreted as a parameter that determined the percentage of those respondents who, having received a positive screening result, indeed might have had depression. All these parameters were studied at different threshold points in order to determine the optimal for screening purposes values. The reliability of the results of the representative sample was assessed using the Fiesher's statistical test $(\mathrm{n}=175 ; * \mathrm{cr}=2.31, \mathrm{p} \leq 0.01)$ for independent samples compared in pairs, at the level of statistical significance of the differences $p \leq 0.01$, taking into account the variance. When comparing the group error probability, the critical level of significance was 0.015 .

Results of application of PHQ-9 screening method to identify depressive conditions among young adults are represented in Table 1.

Table 1.

The level and prevalence of depression during the FP and SP University's students.

\begin{tabular}{llll}
\hline Indicator / Level of Depression Severity & FP, $\%$ & SP, $\%$ & Growth rate, $\%$ \\
\hline Minimal depression & 47.6 & 28.2 & -58 \\
Mild depression & 29.7 & 32.5 & +8.6 \\
Moderate depression & 13.6 & 25.4 & +45 \\
Moderately severe depression & 5.5 & 7.3 & +26 \\
Severe depression & 3.6 & 6.6 & +50 \\
\hline
\end{tabular}

The estimated the data manifest slight rise in SP in comparison with FP. The level of moderate and severe depression increased in nearly $50 \%$ while a minimal depression point decreased by almost half. Moderately severe depression amplified by $26 \%$ whereas mild depression increased slightly.
There were no significant differences in these indicators between the groups of men and women.

Visual change in the level of severity of students' depression in the first online learning period in comparison with the second online learning period (on the basis of PHQ-9) is demonstrated in Figure 1, where FP is marked with a blue line and SP is marked with a red line. 


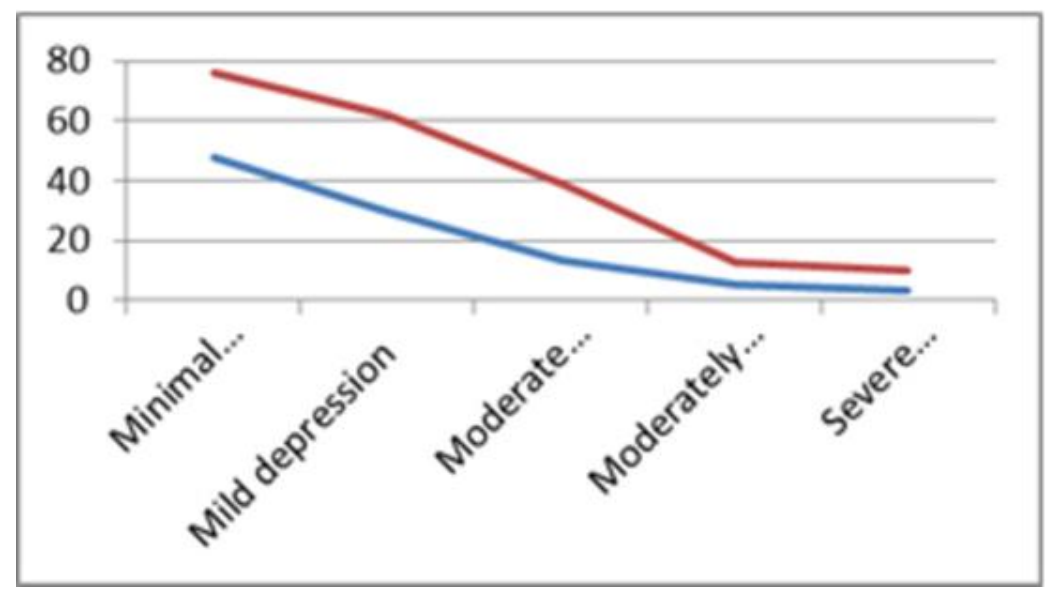

Figure. 1. Correlation of Severity of Depression (as indicated by PHQ-9)

Table 2 shows psychometric scale characteristics of GAD-7. According to the conducted statistical analysis, gender did not significantly affect the survey results. There were no significant differences in these indicators between the groups of men and women. The study revealed that estimated the level of anxiety increased steadily in the SP. The level of severe anxiety redoubled in number. Comparing two periods, the growth in $13 \%$ was characteristic to mild and in $33 \%$ to moderate anxiety respectively, but a mild to moderate point decreased in $22.4 \%$.

Table 2.

The level and prevalence of severity of anxiety during the FP and SP University's students.

\begin{tabular}{llll}
\hline Indicator / Level of Anxiety Severity & FP, $\%$ & SP, $\%$ & Growth rate, $\%$ \\
\hline Minimal anxiety & 49.2 & 41.2 & -8.3 \\
Mild anxiety & 28.3 & 32.3 & +13 \\
Mild to moderate anxiety & 13.2 & 11.6 & -22.4 \\
Moderate anxiety & 6.9 & 10.1 & +33 \\
Severe anxiety & 2.4 & 4.8 & +50 \\
\hline
\end{tabular}

Visual change in the level of severity of students' anxiety in the first online learning period comparing to the second online learning period (on the basis of GAD-7) is presented in Figure 2 where FP is marked with a blue line and SP is marked with a red line.

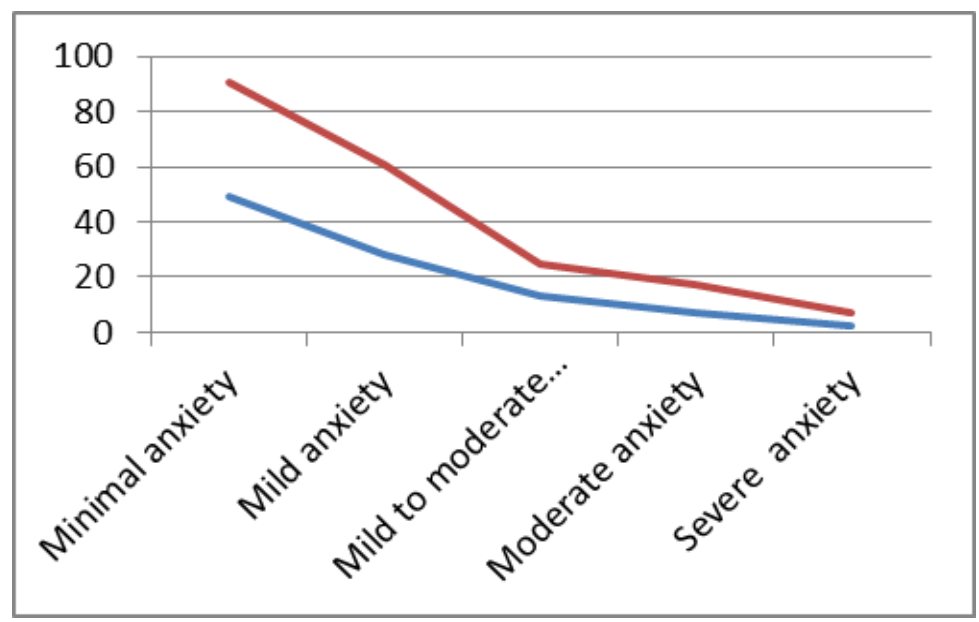

Figure. 2. Correlation of Severity of Anxiety (as indicated by GAD-7) 


\section{AMAZONIA
Investiga}

Thus, it should be noted that the growth rate of stress and anxiety level during SP grew drastically in comparison with FP.

\section{Discussion}

Since March 2020 Yaroslav Mudryi National Law University, as many other higher educational institutions all over the world, started online learning. This process implied various kinds of innovations in the academic routine, which could have an impact on students' quality of life as well as their mental and emotional wellbeing since they are one of the main components of life quality. Some of the research findings are as follows: the data show that during FP 2020 students felt more comfortable and relaxed compared to the SP. The study also indicates emergence of irritability and anxiety and constant rise of the following items. So the authors strongly agree with the idea of S. Galea, R. Merchant, \& N. Lurie (2020) that as a result of physical distancing, lack of interpersonal communication and a restriction in visiting public places, the level of anxiety worsened. The absence of personal off-line communication as well as restrictions and changes in forms of education made students feel anxious and depressed. The study proved that young adults' health is stipulated by a number of factors, such as learning environment, lifestyle, and medical factors.

Following the researchers from the United States of America (C. Son, S. Hegde, A. Smith, X. Wang, \& F. Sasangohar (2020); S. Patrick, L. Henkhaus, J. Zickafoose, K. Lovell, A. Halvorson, S. Loch, M. Letterie, \& M. Davis, (2020)), who discovered deterioration of mental health and increase in the level of stress and anxiety of children (14\%), their parents $(27 \%)$ and school teachers $(52 \%)$ as a result of the Covid-19 outbreak, the authors' findings revealed that more than $50 \%$ of the total participants of the surveys among students were experiencing stress and anxiety. The present study also manifested the obvious necessity in special preventive measures to enhance students' physical and psychological well-being during online learning caused by the pandemic and quarantine measures. However, we suppose very important to pay attention to observations of S. Taylor (2019), F. Silva, J. Sales, \& C. Monteiro (2020) and some other researchers who note that being afraid to be infected and pandemic restrictions can also lead to stress and worsen pre-existing psychiatric states.
The authors' findings has strictly supported the facts stated by Brazilian researchers F. Silva et al. (2020) and others that the pandemic as a challenging factor for mental health caused crucial necessity in elaborating preventive strategies to enhance psychological resilience in the society (Silva et al., 2020). Unfortunately, during the Covid-19 pandemic, the number of people at risk is increasing dramatically, and, after the lockdown period ceases, mental health services are sadly expected to be overwhelmed day by day. Unfortunately, our investigation has proved it.

However, Al-Rabiaah, M. Temsah, Al-Eyadhy, G. Hasan, Al-Zamil and others (2020) in their study on the dependence of Middle East Respiratory Syndrome pandemics and stress suffered by university students established quite different indicators of students' anxiety level: $77 \%$ of low level of anxiety, and $18.4 \%$ of medium level of anxiety.

What is more, the scientists prove that such factors of working environment as multitasking, heavy workload, and focus on emotionally complex assignments and others can cause significant stress, increase anxiety, and impair physical and mental health. And according to the research, three out of five employees have workrelated mental health problems (Business in the Community, 2017). We consider it to be substantial to note that the listed features of working environment are very close to learning environment of students. There is no doubt that they traditionally have some effect on students' mental health and will worsen the studied problems in a pandemic (Sergeant, van Reekum, Sanger, Dufort, Rosic, \& Sanger, 2020).

In addition, due to the development of technology, compared to other age groups young people can be exposed to negative flows caused by the Covid-19 epidemic around the world through internet and social media. This situation can be claimed to make young people psychologically more risky than other age groups. Likewise, young people are thought to have psychological consequences such as loneliness, depression, anger, pessimism, and hopelessness.

It can be said that mental health issues are not considered to be individual cases, but sort of a global sphere, and educators should become more flexible, innovate and adapt to changing situations in order to maintain the human area of global sustainability. 


\section{Practical advice}

Coping with stress and anxiety can be difficult due to the pandemic but crucial in helping students. Certain steps aimed at implementation by teaching staff can be suggested:

- Try to reevaluate workload on the course or task a student is enrolled in.

- Work out precise instructions on courses and extracurricular activities. Set aside enough time to relax.

- Extracurricular activities should involve socializing as it improves one's mood and promotes emotional relief. Among them humorous quizzes, online book reviews, online discussion of reasons causing stress, online interview and zoom meetings can be proposed.

- Tutors should help plan students' time and divide workload into manageable chunks.

In addition, it can be extremely important to find and to involve professional support to deal with stress and anxiety. Professional psychological extra help or giving access to such resources (mental health services), as well as peer counseling, provide relief. Moreover, a healthy lifestyle, hobbies, caring for pets and house plants have a positive impact on stress levels and wellbeing.

\section{Conclusions}

Thus, the present study has examined gradual changes of students' mental and emotional health as one of the main components of their life quality during two periods of distance online learning caused by Covid-19 pandemic (on the basis of several Institutes and faculties of Yaroslav Mudryi National Law University, Kharkiv, Ukraine). The research has provided information for understanding psychological threats caused by modern (inexperienced before) factors such as online learning, Covid-19 pandemic and related quarantine measures among young adults in Ukraine. As mental health (being the basis of an individual's well-being and effective community functioning) is determined by biological, psychological and social factors, it is vital to monitor the impact of distance online learning as well as the pandemic and associated constraints on the psychological well-being of young people. The research has revealed that stress and anxiety level grew drastically if to compare the first and the second stages of online learning periods. That is experiencing stress caused by online learning in terms of the pandemic and quarantine measures, a persons' psychological well-being is badly influenced and can lead to depression let alone deterioration in the quality of life. The current study indicated that lack of socialization and pandemic-related anxiety resulted in changes in students' mental and emotional state regarding depression and anxiety. So in order to enhance mental wellbeing as the basis of students' life quality during online learning in a pandemic situation universities and psychologists should work together to overcome the effects of the pandemic.

The principles of sustainability and development require society's awareness to achieve sustainable well-being. An important tool for achieving this goal can be the use of technology and media. Nevertheless, preparing the youth for the possible future waves of a pandemic is currently the best measure to mitigate the more serious consequences for the mental health of students. It is our responsibility to recognize and cope with these challenges in social and educational sphere to ensure the optimal quality of life for both present and future generations. Finding ways and methods of reducing social consequences of mental disorders can be seen as our future aim.

\section{Abbreviations}

UNESCO, United Nations Educational, Scientific and Cultural Organization; PHQ, Patient Health Questionnaire; GAD, Generalized Anxiety Disorder; FP, First Period; SP, Second Period; WHO, World Health Organization.

\section{Ethics approval and consent to participate}

The research results were obtained with the informed consent of all participants.

\section{Acknowledgment}

The authors thank Yaroslav Mudryi National Law University for technical assistance. We also thank anonymous reviewers for excellent criticism of the article.

\section{Funding}

The authors received no financial support for the research, authorship, and/or publication of this article.

\section{Conflict of interest}

The authors declare no conflict of interest. 


\section{AMAZONDA \\ 1กvestบำ}

Bibliographic references

Akat, M. \& Karataş, K. (2020). Psychological effects of COVID-19 Pandemic on society and its reflections on education. Turkish Studies, 15(4), 1-13. doi: 10.7827/TurkishStudies.44336

Al-Huwailah, A. (2017). Quality of Life and Emotional Intelligence in a Sample of Kuwait University Students. Journal of Education and Practice, 8(3), 180-185. Retrieved April 20, 2021, from https://core.ac.uk/download/pdf/234639792. pdf

Al-Rabiaah, A., Temsah, M. H., Al-Eyadhy, A. A., Hasan, G. M., Al-Zamil, F., Al-Subaie, S., Alsohime, F., Jamal, A., Alhaboob, A., Al-Saadi, B., \& Somily, A. M. (2020). Middle East Respiratory Syndrome-Corona Virus (MERS-CoV) associated stress among medical students at a university teaching hospital in Saudi Arabia. Journal of Infection and Public Health, 13 (5), 687-691. doi: 10.1016/j.jiph.2020.01.005

Aristovnik, A., Keržič, D., Ravšelj, D., Tomaževič, N., \& Umek, L. (2020). Impacts of the COVID-19 pandemic on life of higher education students: a global perspective. Sustainability, $12, \quad 8438$. doi: 10.3390/su12208438

Bozkurt, A., \& Sharma, R. C. (2020). Emergency remote teaching in a time of global crisis due to Corona Virus pandemic. Asian Journal of Distance Education, 15(1), i-iv. doi: 10.5281/zenodo. 3778083

Brooks, S.K., Webster, R.K., \& Smith, L.E. (2020). The Psychological Impact of Quarantine and How to Reduce It: Rapid Review of the Evidence. Lancet, 14(395), 912-920. doi: 10.1016/S01406736(20)30460-8

Business in the Community. (2017). Mental Health report: National employee mental wellbeing survey findings. Retrieved April 21, 2021, from https://www.activehw.co.uk/uploads/bitcme ntal-health-at-work-report-2017.pdf

Cao, W., Fang, Z., Hou, G., Han, M., Xu, X., \& Dong, J. (2020). The psychological impact of the COVID-19 epidemic on college students in China. Psychiatry Res., May (287), 112934.

doi: 10.1016/j.psychres.2020.112934.

Galderisi, S., Heinz, A., Kastrup, M., Beezhold, J., \& Sartorius, N. (2015). Toward a new definition of mental health. World Psychiatry, 14(2), 231-233. doi: 10.1002/wps.20231
Galea, S., Merchant, R., \& Lurie, N. (2020). The Mental Health Consequences of COVID-19 and Physical Distancing: The Need for Prevention and Early Intervention. JAMA Intern Med., 180(6), 817-818. doi: 10.1001/jamainternmed.2020.1562

Holubnycha, L., Miasoiedova, S., Nesterenko, K. (2018). Health Saving Technology at Foreign Language Lessons with University Students. Research Journal of Pharmaceutical, Biological and Chemical Sciences, 9(6), 1709 - 1718. Retrieved April 20, 2021, from https://www.rjpbcs.com/pdf/2018_9(6)/[279 ].pdf

Khatuntseva, S., Kabus, N., Portyan, M., Zhernovnykova, O., Kara, S., \& Knysh, S. (2020) The Method of Forming the HealthSaving Competence of Pedagogical Universities' Students. Romanian Journal for Multidimensional Education, 12(1), 185-197. doi: $10.18662 / \mathrm{rrem} / 208$

Kroenke, K., Spitzer, R.L., Williams, J.B.W., \& Löwe, B. (2010) The Patient Health Questionnaire Somatic, Anxiety, and Depressive Symptom Scales: a systematic review. General Hospital Psychiatry, 32, 345-359.

10.1016/j.genhosppsych.2010.03.006

Lai, J., Ma, S., \& Wang, Y. (2020). Factors Associated With Mental Health Outcomes Among Health Care Workers Exposed to Coronavirus Disease 2019. JAMA Netw Open, 3(3), e203976. doi: 10.1001/jamanetworkopen.2020.3976

London, R.T. (2020). Is COVIDE19 leading to a mental illness pandemic? MDedge Infectious disease, March 25, 2020. Retrieved April 20, 2021,

from https://www.mdedge.com/infectiousdisease/

Michielsen, H. J., De Vries, J., \& Van Heck, G. L. (2003). Psychometric qualities of a brief self-rated fatigue measure. The Fatigue Assessment Scale. Journal of Psychosomatic Research, 54(4), 345-352.

Mukhin, M., Sergeeva, M., \& Ogurechnikova, N. (2020). Health-Saving Technologies in Education. Journal of Southwest Jiaotong University, 55(1).

Nicola, M., Alsafi, Z., Sohrabi, C., Kerwan, A., Al-Jabir, A., Iosifidis, C., \& Agha, R. (2020) The socio-economic implications of the coronavirus and COVID-19 pandemic: A review. International Journal of Surgery, 78, 185-193. doi: 10.1016/j.ijsu.2020.04.018

Patrick, S. W., Henkhaus, L. E., Zickafoose, J. S., Lovell, K., Halvorson, A., Loch, S., Letterie, M., and Davis, M. M. (2020). Well-being of Parents and Children During the COVID-19 Pandemic: A National Survey. Pediatrics, 
146(4), e2020016824. doi: https://doi.org/10.1542/peds.2020-016824

Pidchasov, Y.V. (2016). Psychological features of construction of educational process with application of remote educational technologies. In Theory and Practice of Using the Learning Management System (pp. 231-240). Kyiv: KNU.

Pocnet, C., Dupuis, M., Congard, A., \& Jopp, D. (2017). Personality and its links to quality of life: Mediating effects of emotion regulation and self-efficacy beliefs. Motiv Emot 41, 196-208. Retrieved April 20, 2021, from https://doi.org/10.1007/s11031-017-9603-0

Saei Ghare Naz, M., Ramezani Tehrani, F., Behroozi Lak, T., Mohammadzadeh, F., Nasiri, M., Kholosi Badr, F., \& Ozgoli, G. (2020). Quality of Life and Emotional States of Depression, Anxiety and Stress in Adolescents with Polycystic Ovary Syndrome: A Cross-Sectional Study. Psychology Research and Behavior Management, 13, 203-209. Retrieved April 22, 2021, from https://doi.org/10.2147/PRBM.S241192

Savage, M. J., James, R., Magistro, D., Donaldson, J., Healy, L. C., Nevill, M., \& Hennis, P. J. (2020). Mental health and movement behaviour during the COVID-19 pandemic in UK university students: Prospective cohort study. Mental Health and Physical Activity, 19, 100357. doi: 10.1016/j.mhpa.2020.100357

Sergeant, A., van Reekum, E.A., Sanger, N., Dufort, A., Rosic, T., Sanger, S., Lubert, S., Mbuagbaw, L., Thabane, L., Samaan, Z. (2020). Impact of COVID-19 and other pandemics and epidemics on people with preexisting mental disorders: a systematic review protocol and suggestions for clinical care. BMJ Open, 10(9), e040229. doi: 10.1136/bmjopen-2020-040229

Silva Junior, F.J.G., Sales, J.Ce.S., Monteiro., C.Fd.S., Costa, A.P.C., Campos, L.R.B., Miranda, P.I.G., Monteiro, T.A.S., Lima, R.A.G., $\quad \&$ Lopes-Junior, L.C. (2020). Impact of COVID-19 pandemic on mental health of young people and adults: a systematic review protocol of observational studies. BMJ Open, 10(7), e039426. doi: 10.1136/bmjopen-2020039426
Son, C., Hegde, S., Smith, A., Wang, X., Sasangohar, F. (2020). Effects of COVID-19 on college students' mental health in the United States: interview survey study. Journal of Medical Internet Research., 22(9), e21279. doi: 10.2196/21279

Sood, S. (2020). Psychological effects of the Coronavirus disease-2019 pandemic. Research \& Humanities in Medical Education, 7, 23-26. Retrieved April 20, 2021, from https://www.rhime.in/ojs/index.php/rhime/ar ticle/view/264

Spitzer, R.L., Kroenke, K., Williams, J.B.W., \& Lowe, B. (2006). A brief measure for assessing generalized anxiety disorder. Archives of Internal Medicine, 166, 10921109. doi: 10.1001/archinte. 166.10.1092

Taylor, S. (2019). The psychology of pandemics: Preparing for the next global outbreak of infectious disease. Cambridge Scholars Publishing.

Theofilou, P. (2013) Quality of life: definition and measurement. Europe's Journal of Psychology, 9(1), 150-162. https://citeseerx.ist.psu.edu/viewdoc/downlo ad?doi=10.1.1.299.4629\&rep=rep1\&type $=p$ df

UNESCO. (2020). Education: From disruption to recovery. Retrieved April 20, 2021, from https://en.unesco.org/covid19/educationresp onse

WHOQOL Group. (1997). Programme on Mental Health. Measuring Quality of Life. Geneva: World Health Organization. Retrieved April 20, 2021, from https://www.who.int/mental_health/media/6 8.pdf

Wang, C., Pan, R., Wan, X., Tan, Y., Xu, L., Ho, C. S., \& Ho, R. C. (2020). Immediate psychological responses and associated factors during the initial stage of the 2019 corona virus disease (COVID-19) epidemic among the general population in China. International Journal of Environmental Research and Public Health, 17, 1729. doi: 10.3390/ijerph17051729

World Health Organization. (2004). Promoting mental health: concepts, emerging evidence, practice (Summary Report). Geneva: World Health Organization. 